\title{
Whole-body magnetic resonance imaging in children: state of the art*
}

Ressonância magnética de corpo inteiro em pediatria: estado da arte

\section{Sara Reis Teixeira ${ }^{1}$, Jorge Elias Junior ${ }^{2}$, Marcello Henrique Nogueira-Barbosa ${ }^{3}$, Marcos Duarte Guimarães ${ }^{4}$, Edson Marchiori ${ }^{5}$, Marcel Koenigkam Santos ${ }^{1}$}

Teixeira SR, Elias Jr J, Nogueira-Barbosa MH, Guimarães MD, Marchiori E, Koenigkam-Santos M. Whole-body magnetic resonance imaging in children: state of the art. Radiol Bras. 2015 Mar/Abr;48(2):111-120.

Abstract Whole-body imaging in children was classically performed with radiography, positron-emission tomography, either combined or not with computed tomography, the latter with the disadvantage of exposure to ionizing radiation. Whole-body magnetic resonance imaging (MRI), in association with the recently developed metabolic and functional techniques such as diffusion-weighted imaging, has brought the advantage of a comprehensive evaluation of pediatric patients without the risks inherent to ionizing radiation usually present in other conventional imaging methods. It is a rapid and sensitive method, particularly in pediatrics, for detecting and monitoring multifocal lesions in the body as a whole. In pediatrics, it is utilized for both oncologic and non-oncologic indications such as screening and diagnosis of tumors in patients with genetic syndromes, evaluation of disease extent and staging, evaluation of therapeutic response and post-therapy follow-up, evaluation of non neoplastic diseases such as multifocal osteomyelitis, vascular malformations and syndromes affecting multiple regions of the body. The present review was aimed at describing the major indications of whole-body MRI in pediatrics added of technical considerations.

Keywords: Magnetic resonance imaging; Whole-body MRI; Diffusion-weighted imaging; Pediatrics.

Resu mo A avaliação de corpo inteiro em crianças era classicamente realizada com radiografias simples, cintilografia e tomografia por emissão de pósitrons combinada ou não à tomografia computadorizada, estes com a desvantagem de exposição à radiação ionizante. A ressonância magnética de corpo inteiro (RMCl), associada ao desenvolvimento de técnicas metabólicas e funcionais como difusão, trouxe a vantagem de uma avaliação global do paciente pediátrico sem os riscos da radiação ionizante habitualmente presente nos métodos radiológicos convencionais. A RMCl é um método rápido e sensível, com aplicação especial na área de pediatria na detecção e no monitoramento de lesões multifocais no corpo como um todo. Em pediatria, esta técnica é utilizada tanto em oncologia - no diagnóstico e rastreamento de tumores em pacientes portadores de síndromes genéticas, na avaliação da extensão de doenças e estadiamento oncológico, na avaliação da resposta terapêutica e no seguimento pós-terapêutico - como em lesões não neoplásicas - osteomielite multifocal, malformações vasculares e síndromes que comprometam múltiplas regiões do corpo. Esta revisão tem como objetivo mostrar as principais indicações do exame na população pediátrica e técnica de realização.

Unitermos: Ressonância magnética; Ressonância magnética de corpo inteiro; Difusão; Pediatria.

\section{INTRODUCTION}

Until recently, whole-body imaging in children was performed only with plain radiography, scintigraphy and positron-emission tomography (PET), either in combination or not with computed tomography (CT). However, such imaging methods present the disadvantage of radiation exposure,

* Study developed at Centro de Ciências das Imagens e Física Médica (CCIFM) do Hospital das Clínicas da Faculdade de Medicina de Ribeirão Preto da Universidade de São Paulo (HCFMRP-USP), Ribeirão Preto, SP, Brazil.

1. PhD, Attending Physician at Centro de Ciências das Imagens e Física Médica (CCIFM) do Hospital das Clínicas da Faculdade de Medicina de Ribeirão Preto da Universidade de São Paulo (HCFMRP-USP), Ribeirão Preto, SP, Brazil.

2. PhD, Associate Professor, Division of Radiology, Faculdade de Medicina de Ribeirão Preto da Universidade de São Paulo (HCFMRP-USP), Ribeirão Preto, SP, Brazil.

3. PhD, Professor, Division of Radiology, Faculdade de Medicina de Ribeirão Preto da Universidade de São Paulo (HCFMRP-USP), Ribeirão Preto, SP, Brazil.

4. PhD, Attending Physician at Hospital Heliópolis and A.C.Camargo Cancer Center, São Paulo, SP, Brazil.

5. PhD, Full Professor, Division of Radiology, Universidade Federal Fluminense (UFF), Niterói, RJ, Brazil. particularly for children who are more susceptible to carcinogenic effects, even with low ionizing radiation doses ${ }^{(1)}$.

Magnetic resonance imaging (MRI) has increasingly gained relevance in evaluation of pediatric patients since it does not use ionizing radiation. Additionally, development of MRI techniques, increase in availability of high-field apparatuses, improvement of body coils and introduction of new softwares, have reduced scan time and allowed employment of this tool in whole-body evaluation ${ }^{(2,3)}$.

In pediatrics, whole-body MRI (WBMRI) was initially used for staging lymphomas ${ }^{(4)}$, but its use has currently been expanded for evaluation of other systemic diseases. Besides assessment of cancer in children, WBMRI stands out in the investigation of inflammatory and/or infectious processes ${ }^{(5,6)}$,

Mailing Address: Dra. Sara Reis Teixeira. CCIFM - FMRP. Avenida Bandeirantes, 3900, Monte Alegre. Ribeirão Preto, SP, Brazil, 14049-900. E-mail: steixeira@hcrp. usp.br.

Received February 3, 2014. Accepted after revision March 24, 2014. 
osteonecrosis $^{(7)}$, soft tissue lesions such as myositis ${ }^{(8,9)}$, neurofibromatosis ${ }^{(10)}$, vascular malformations and multiple angiomatoses $^{(11,12)}$, non-accidental traumas ${ }^{(13)}$, body fat composition $^{(14)}$ and virtual autopsy ${ }^{(15,16)}$.

WBMRI is performed with rapid sequences usually acquired in one or two planes with a primary objective of screening, and therefore it is not used to show anatomical details, differently from an imaging study targeted to a specific body region ${ }^{(17)}$. By means of traditional rapid morphological T1- and T2-weighted images, or inversion recovery sequences such as short tau inversion-recovery (STIR), in conjunction with functional techniques such as diffusionweighted imaging (DWI), one can obtain a whole-body morphological/functional mapping, providing relevant information on the burden and level of activity of a determined disease ${ }^{(18-20)}$.

The aim of this study is to present an updated review on utilization of WBMRI in pediatric population.

\section{TECHNICAL CONSIDERATIONS}

Even without a global consensus about it, WBMRI is usually performed with acquisition of one, two, three or more image sets, depending on size of the patient and on region to be scanned. Subsequently, images are coupled with the aid of specific softwares to form a whole-body image ${ }^{(21,22)}$ (Figure 1). Sometimes, patient's repositioning is required, depending on his/her size and on type of coil which was used. WBMRI scans should be preferentially performed in highfield (1.5 T or more) MRI scanners with surface or body coil. Utilization of a gliding tabletop, tabletop extender, integrated coils ${ }^{(3,23)}$ or body surface coil with spacers ${ }^{(24)}$ is preferable since it significantly reduces scan time and necessity of repositioning the patient during examination. Use of integrated coils provides best signal noise ratio and field homogeneity allowing for further investigation of a specific region in a single scan ${ }^{(25)}$.

Sedation or immobilization of neonates, infants and other non-collaborative patients should follow local protocols. Patients should be scanned from head to toe, in supine position, with extended legs and arms aligned along the body (Figure 2). In the case of larger patients, aliasing artifacts might impair image quality. Thus, it may be necessary to acquire images of upper limbs positioned above the head and use specific sequences to evaluate the feet ${ }^{(3)}$ (Figure 2).
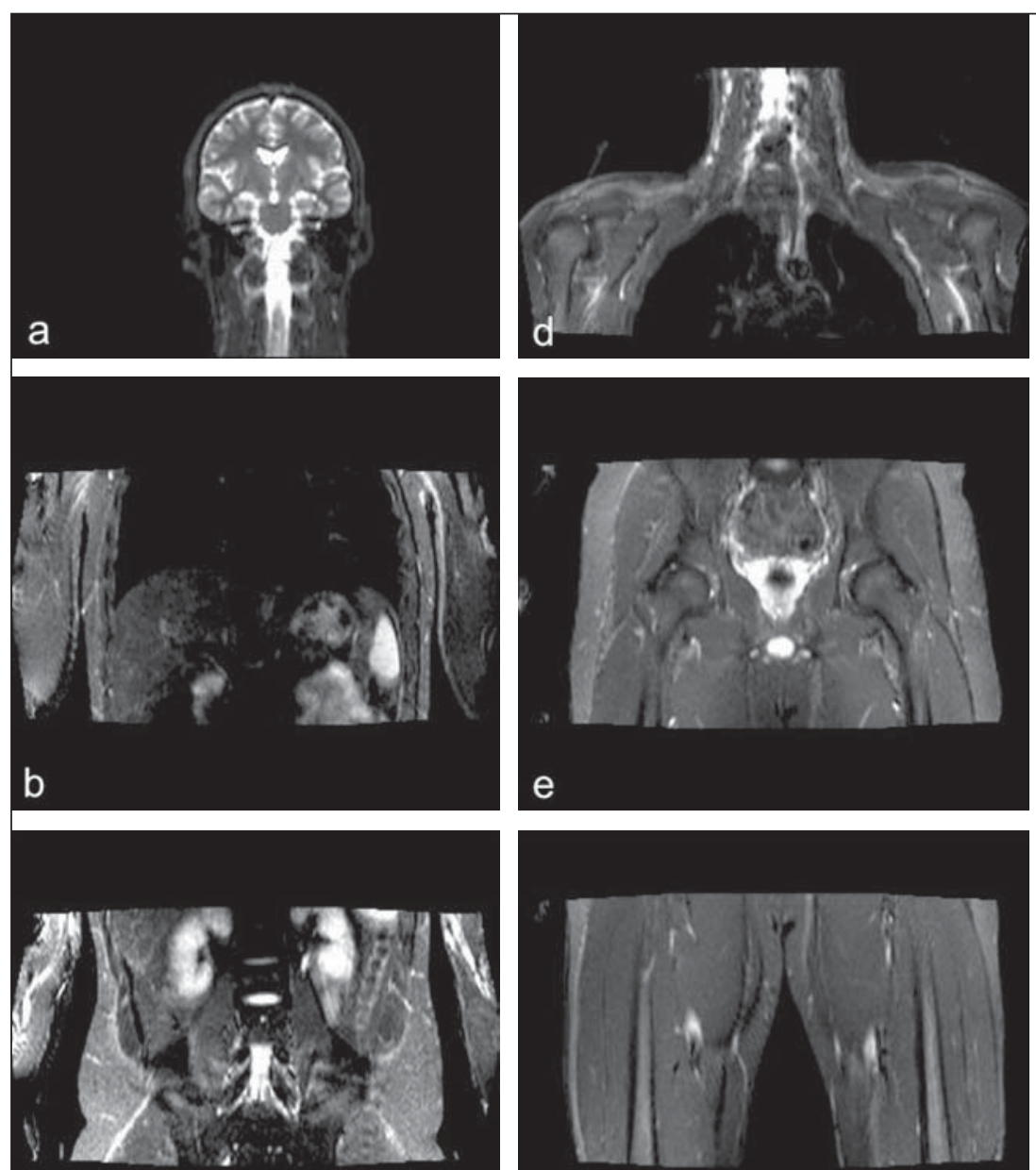

C
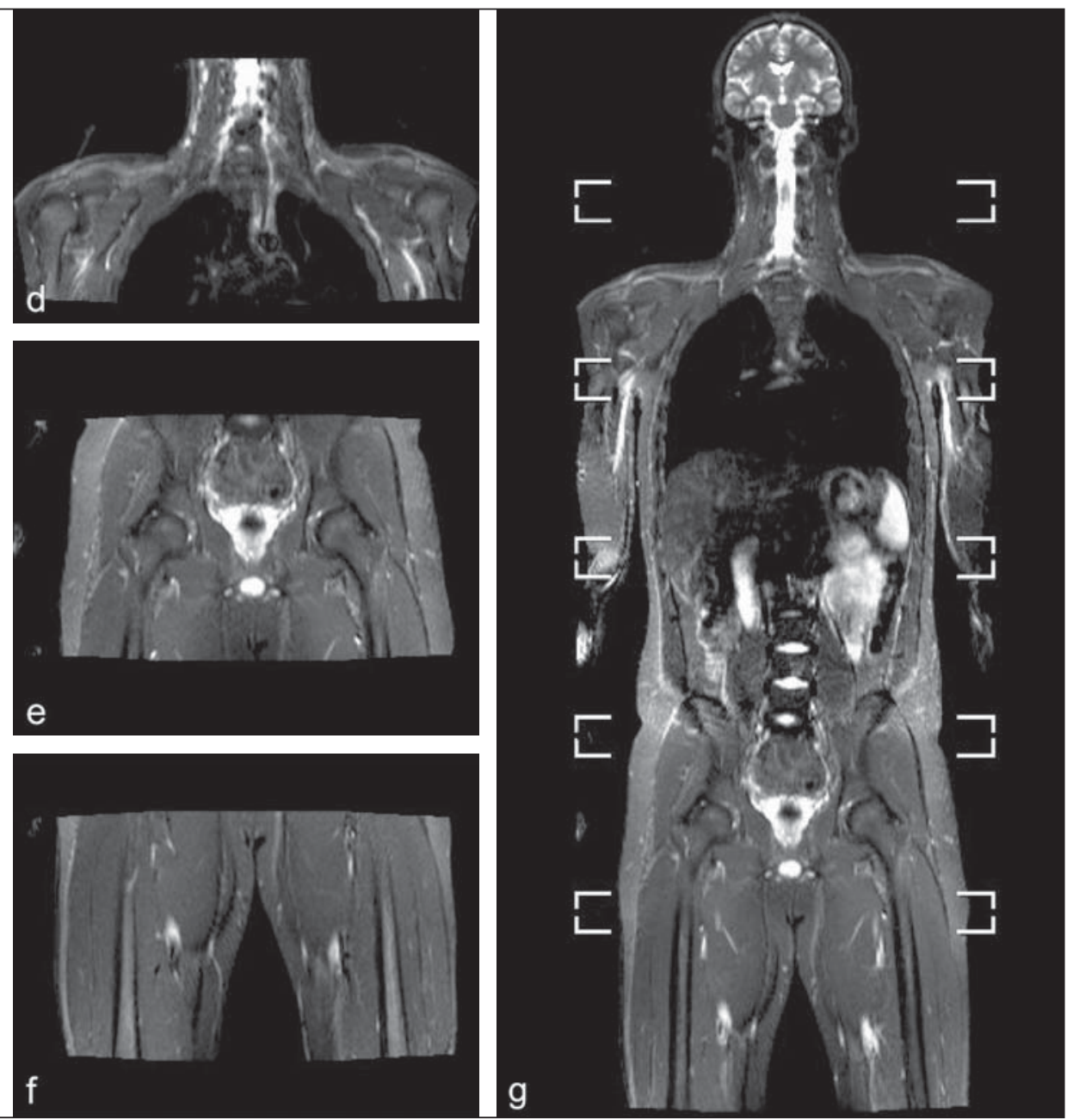

Figure 1. Image acquisition. Re-staging of a 18-year-old boy with lymphoma. STIR block imaging acquisition (a-f) and coronal single image reformatted using MRI system's software (Philips. MobiView) (g). 


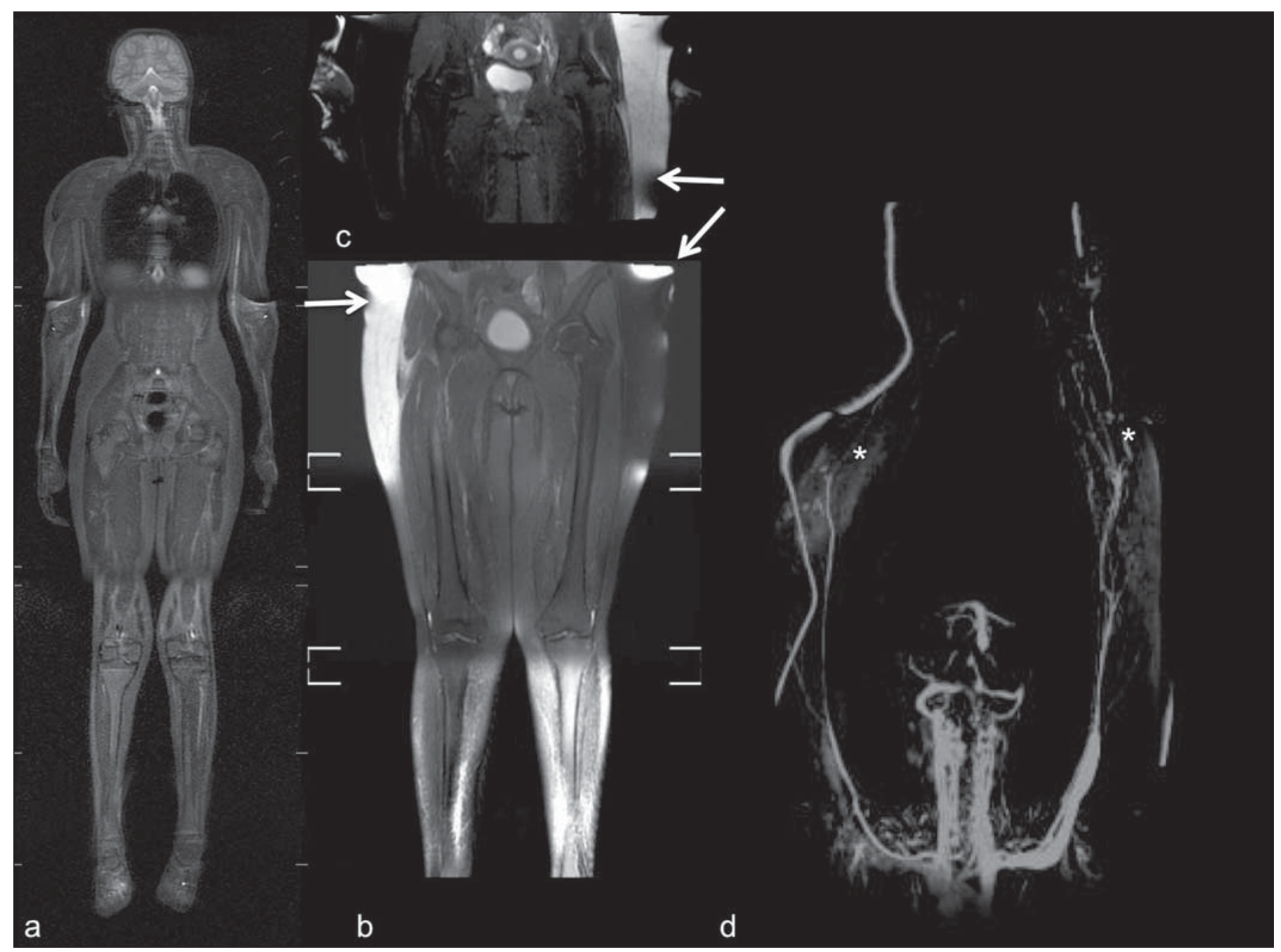

Figure 2. Patient positioning. Sixteen year-old girl referred for investigation of peripheral vascular malformations. Figure a (coronal STIR reformatted image) shows usual patient positioning with extended legs and arms adjacent to body. On Figures $\mathbf{b}$ (coronal STIR lower limbs section reformatted image) and $\mathbf{c}$ (imaging block showing pelvis) aliasing artifacts were noted (arrows). Upper limbs (asterisk) had to be positioned above the head for better image quality (d, post-gadolinium injection angiography).

Cardiac and respiratory gated sequences may be useful to avoid artifacts resulting from physiological thoracic and abdominal motion ${ }^{(21,26)}$.

Coronal is the preferential acquisition plane for baseline WBMRI, because of faster acquisition time in addition to more accurate evaluation of long bones. However, coronal plane has some limitations in evaluation of the thoracic cage, sternum, skull and vertebral spine ${ }^{(27)}$. Moreover, it may have lower sensitivity as compared with axial plane to detect target lesions ${ }^{(28)}$. Therefore, additional sequences acquired in sagittal plane for spine and feet or axial plane for chest and abdomen may be necessary, depending on clinical indication.

Selection of sequence type is determined by clinical indication and by main target tissues to be investigated in certain clinical settings. In most centers, baseline sequences include turbo spin-echo (TSE) T2-weighted sequences with fat saturation or STIR in coronal plane. STIR technique is preferred because of its greater signal homogeneity and higher sensitivity for detecting metastatic lesions as compared with $\operatorname{TSE}^{(4,29-31)}$, due to supression of the stationary tissue and not only fat tissue ${ }^{(4)}$. When needed, TSE T2-weighted sequences are performed in axial plane, since they are faster than STIR.

In order to increase study specificity, TSE T1-weighted sequences should be acquired in coronal plane. Gradientecho T1-weighted sequences are faster and might be useful in diagnosis of metastatic bone marrow lesions, but their sensitivity and contrast resolution are lower compared to TSE sequences ${ }^{(23)}$. Knowledge and familiarization with areas of hematopoietic bone marrow and fat transformation are extremely important for correct interpretation of WBMRI or MRI of any region of the body in pediatrics ${ }^{(3,32)}$. In this context, T1-weighted sequences are essential in evaluation of normal bone marrow conversion and in differentiation from metastatic lesions ${ }^{(33)}$. Some centers use T1-weighted sequence after intravenous gadolinium injection to evaluate cancer, but this sequence is not routinely performed as it extends scan time. In addition, its effectiveness in increasing method accuracy is still to be proved ${ }^{(3,34)}$. However, in 
examinations requiring angiographic evaluation, use of intravenous contrast medium is recommended ${ }^{(35)}$ (Figure 3).

Functional sequences like DWI have been increasingly employed in WBMRI. DWI with single-shot echo-planar imaging (SSh EPI) can provide information on cellularity and tissue necrosis ${ }^{(36)}$. Such sequences are based on random motion of water molecules through biological tissues leading to phase dispersion of spins, resulting in signal loss at diffusion-sensitive sequence. Signal intensity of a studied region can be quantitatively calculated by means of apparent diffusion coefficient (ADC) values, expressed in square millimeter per second $\left(\mathrm{mm}^{2} / \mathrm{s}\right)^{(18,37)}$. DWI in association with fat saturation and acquisition of multiple axial sections with a high number of excitations (DWIBS) ${ }^{(37)}$ is currently the

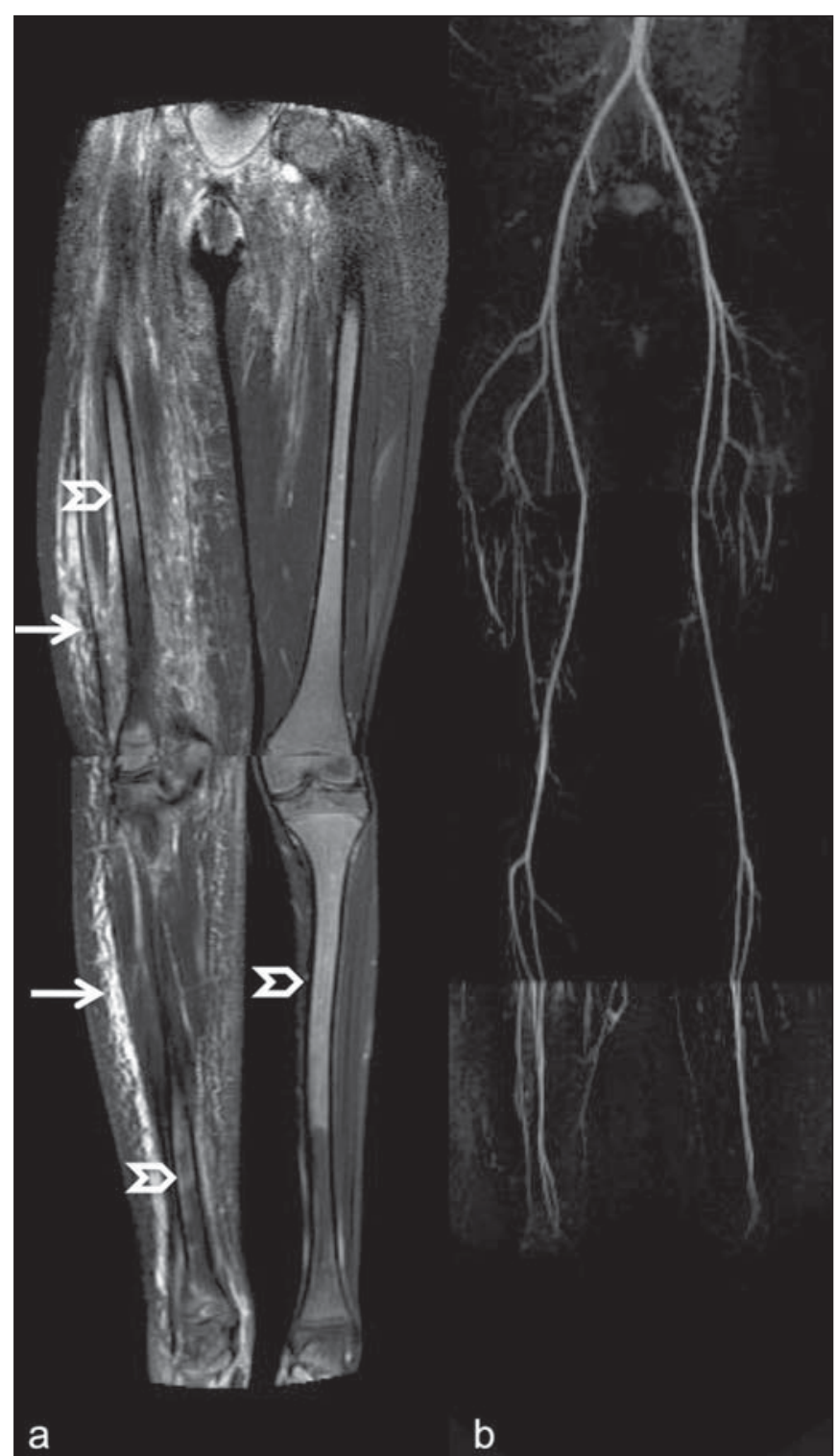

Figure 3. Lower limbs, coronal STIR (a) and magnetic resonance post-gadolinium angiogram reconstruction (b) of a 14-year-old girl for assessment of multiple vascular malformations. No fistulas or arteriovenous malformations were detected on arterial angiogram, confirming hypothesis of low flow vascular malformations. Diffuse hypersignal from soft tissues is observed, particularly at right (arrows) and in bone marrow of lower limbs, which was not noticeable at other imaging methods. most frequently technique used in WBMRI, and has been object of study in multiple clinical scenarios ${ }^{(38,39)}$ (Figure 4).

Regardless of clinical indication, WBMRI should be rapid, most accurate as possible and should not exceed 50 minutes in total duration ${ }^{(26)}$. Ideally, scan should be performed with a minimum of sequences - only one, if possible -, and, in pediatrics, coronal STIR is preferable ${ }^{(4,6,31)}$ (Figure 4).

\section{MAIN WBMRI INDICATIONS IN PEDIATRICS}

\section{Pediatric cancer patient}

The ability to detect primary or secondary lesions in brain, cervical region, thoracic and abdominal organs, bone marrow and musculoskeletal system using a single scan, was one of the factors that propelled development of WBMRI in pediatrics $^{(3,26)}$. Indications for WBMRI depend on type of neoplasia and on disease's stage. In several oncological diseases, WBMRI is used on initial evaluation ${ }^{(22,40,41)}$, screening, staging, evaluation of therapeutic response and posttherapy follow-up ${ }^{(22,26,42)}$.

WBMRI sensitivity is similar to PET/CT in staging of different neoplasias and superior to other imaging methods such as CT, gallium scintigraphy or bone scintigraphy, both in evaluation of bone metastases and extraosseous metastases $^{(41,43-45)}$. WBMRI has the capacity to evaluate wholebody bone marrow, detecting neoplastic sites compromised either by primary tumor or metastasis ${ }^{(46)}$ (Figure 5).

WBMRI has a good diagnostic accuracy for evaluation of therapeutic response in cancer patients ${ }^{(47,48)}$. Increase in ADC value suggests a good response after chemotherapy or radiotherapy and has already been described for brain tumors, liver tumors and sarcomas ${ }^{(36,48)}$. In lymphomas, there is a decrease in tumor volume at morphological sequences and increase in ADC values at DWI sequences ${ }^{(41,43)}$ (Figure 6).

WBMRI can also be used for differentiating between post-treatment fibrosis and viable tumor ${ }^{(49)}$, and for detecting complications.

\section{Cancer screening in at-risk population}

Cancer screening aims to detect cancer before symptoms appear or in early disease stage when treatment and cure are still possible ${ }^{(50)}$. Screening with WBMRI should be applied to a pediatric population at-risk for developing tumors, like in some hereditary syndromes (e.g. multiple endocrine neoplasia types I and II, von Hippel-Lindau syndrome, family adenomatous polyposis and Li-Fraumeni syndrome ${ }^{(51,52)}$.

\section{Non-neoplastic multifocal bone and soft-tissue lesions}

WBMRI allows for defining lesions distribution pattern, their quantification and shows the the best site for biopsy.

In Langerhans' cell histiocytosis, WBMRI can be used to evaluate extent of bone compromise and in follow-up of patients, with similar or superior sensitivity, specificity and accuracy compared to traditional methods, such as bone scintigraphy, CT, metaiodobenzilguanidine scan and PET/ $\mathrm{CT}^{(22,53)}$. 


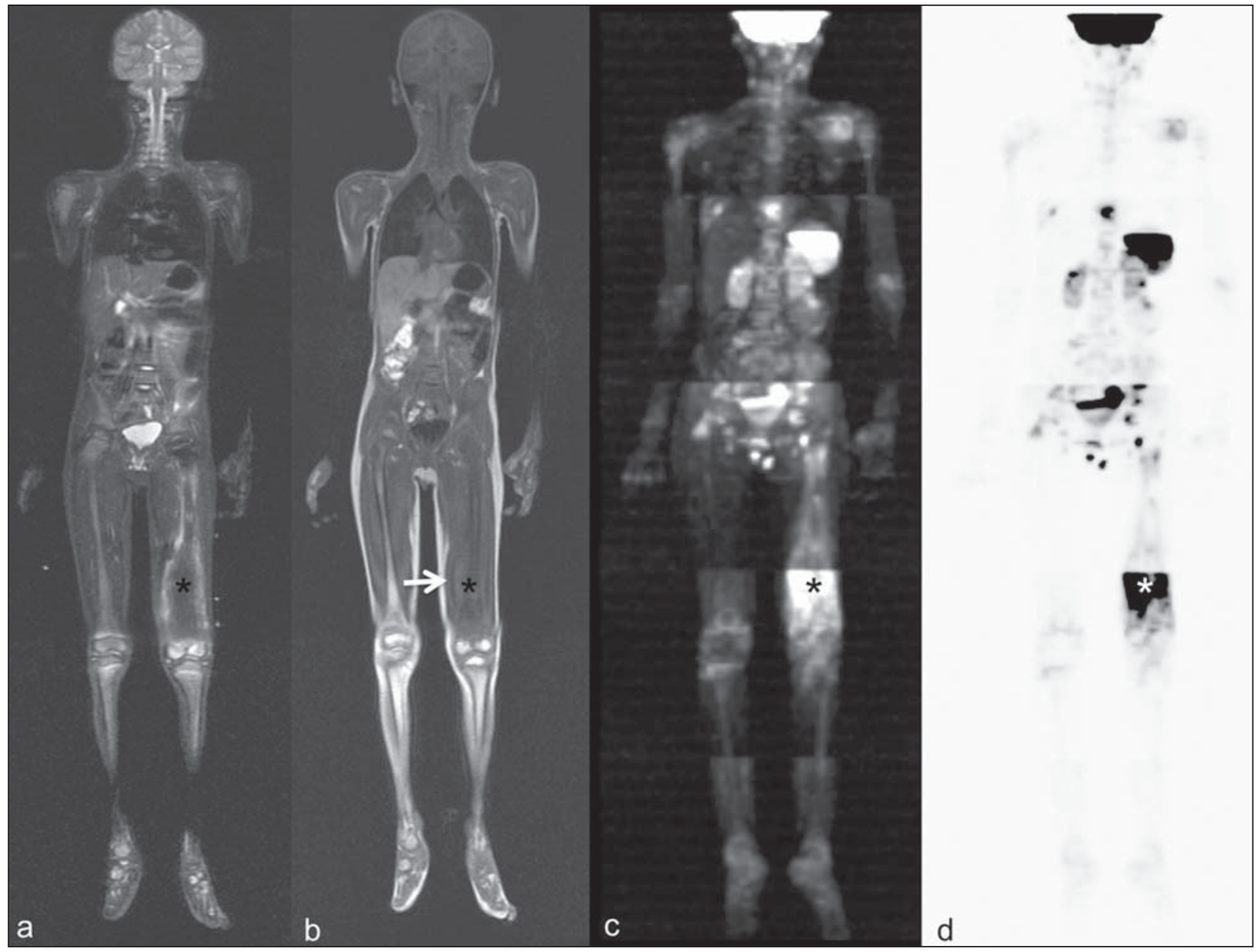

Figure 4. Staging of osteoblastic osteosarcoma on left distal femoral diaphysis (asterisk) in a six-year-old boy. There is proeminent spiculated periosteal reaction (arrow) at plain radiography, with soft tissue components and diffusion restriction on MRI (c,d). There are no secondary distant lesions or skip lesions. a: coronal STIR sequence; b: coronal T1-weighted sequence; c: coronal DWIBS; d: inverted black-and-white gray scale DWIBS.

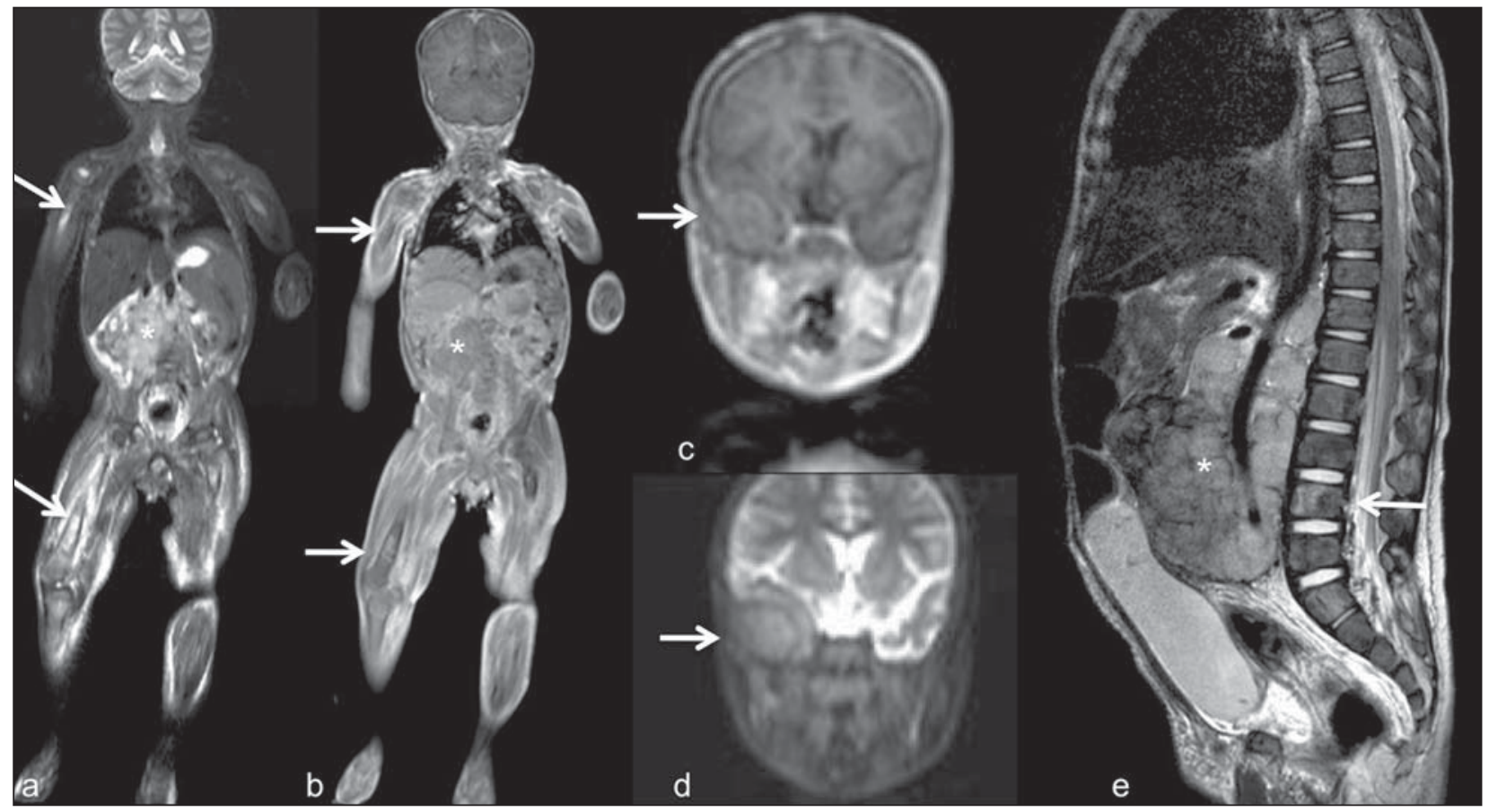

Figure 5. Staging of abdominal neuroblastoma (asterisks) in 19-month-old boy. There are multiple bone metastases (arrows) in upper and lower limbs, skull and vertebral spine. $\mathbf{a}$ and $\mathbf{d}$ : coronal STIR sequence; $\mathbf{b}$ and $\mathbf{c}$ : coronal T1-weighted gradiente-echo sequence; e: sagittal TSE T2-weighted sequence showing the spine. 


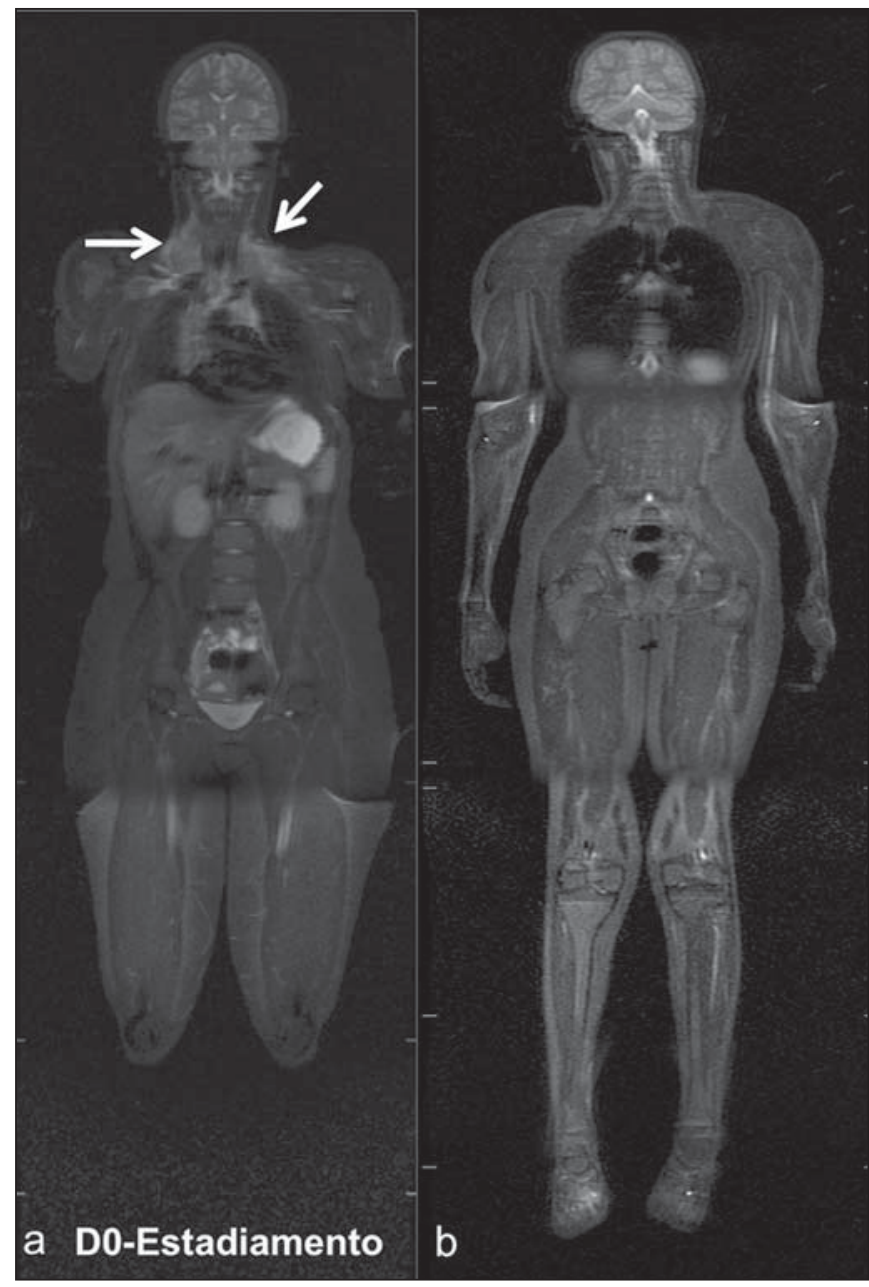

Figure 6. Staging of 17-year-old patient with lymphoma, presenting with enlargement of multiple cervical and mediastinal lymph nodes (arrows) (a). Note regression of lymphadenopathy at day 180 following initiation of therapy (b). a and $\mathbf{b}$ : coronal STIR.

Also, WBMRI is very useful in diagnosis and follow-up of patients with multifocal osteomyelitis ${ }^{(54)}$ (Figure 7) and multifocal osteonecrosis, which generally is secondary to or occur as a side effect of high chemotherapy doses and use of corticoids. WBMRI can show multiple lesions in asymptomatic patients ${ }^{(7)}$, allowing for early treatment and prevention of complications.

In patients at high risk for developing multifocal lesions (post-transplant disorders, sickle cell disease patients, neonates) or in cases of severe infectious processes, such as necrotizing fasciitis or septic shock in unconscious or sedated patients whose clinical follow-up is difficult, WBMRI plays an important role ${ }^{(55)}$. In addition to an accurate assessment of bone lesions, it equally allows for detecting associated extraosseous lesions, such as septic pulmonary emboli, splenic abscesses and soft tissue collections ${ }^{(55)}$.

Even if plain radiography still is the gold standard method in evaluation of non-accidental trauma, WBMRI can aid specificity in detection of medullary bone marrow edema, traumatic liver injuries, hemothorax and intracranial extraaxial fluid collections ${ }^{(13)}$.

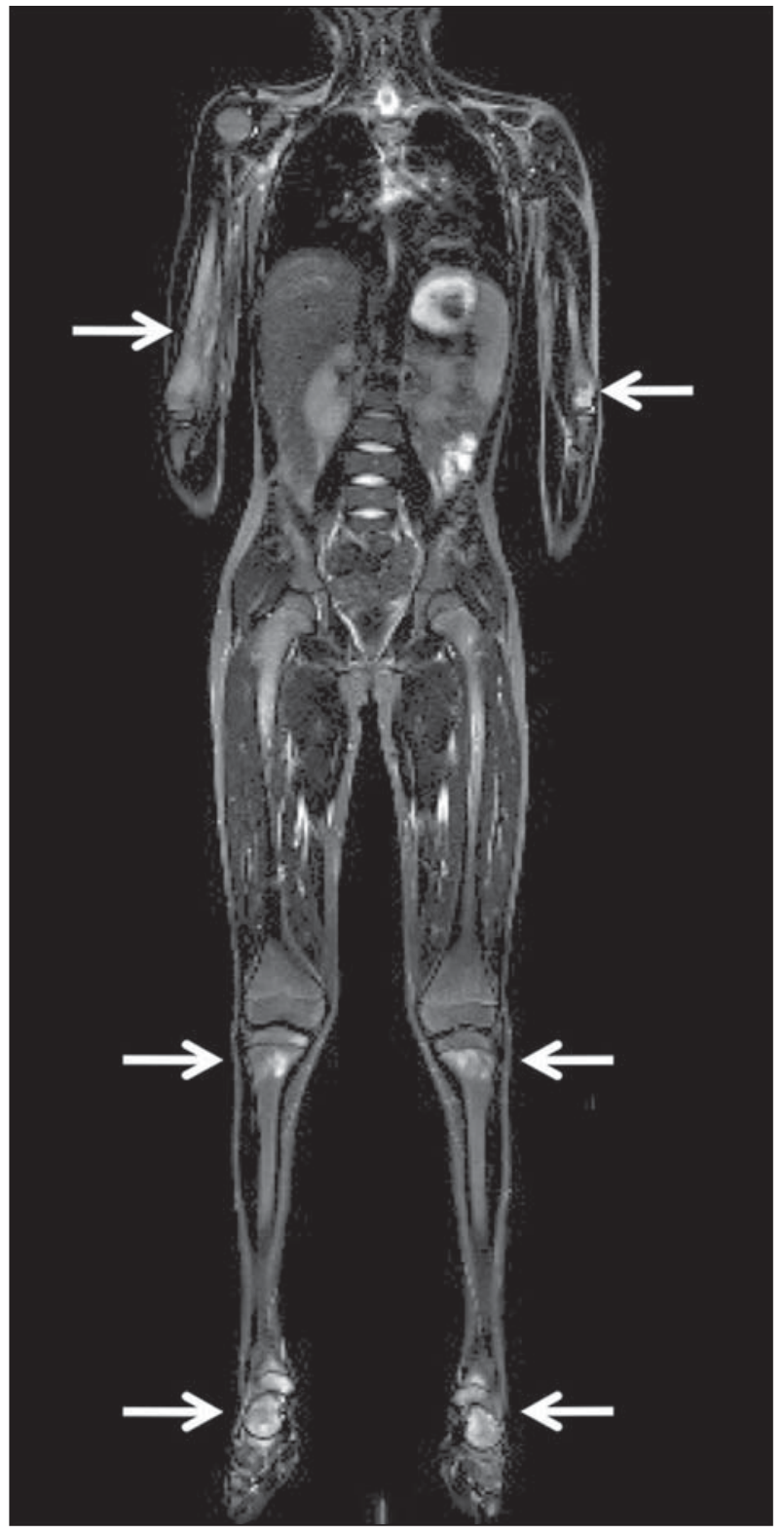

Figure 7. Recurrent multifocal osteomyelitis in a 8-year-old boy. Multiple focal bone lesions (arrows) and bone remodelling of the right humerus. Coronal wholebody STIR MR image.

Patients with myopathies (e.g. myositis, polymyositis, dermatopolymyositis and muscle dystrophies) may also benefit from WBMRI, which can appropriately show disease distribution pattern, best site for biopsy and help in posttherapy follow-up ${ }^{(8,9)}$.

Follow-up of patients with neurofibromatosis has been studied by several groups, considering that WBMRI can accurately assess burden of plexiform neurofibromas, allow-

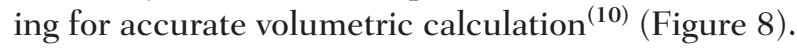

\section{Vascular malformations}

Diffuse vascular malformations (Figure 3), such as hemangiomatosis and lymphangiomatosis (Figure 9), can be assessed with WBMRI. Considering that such lesions may affect different compartments, including skin, subcutaneous 


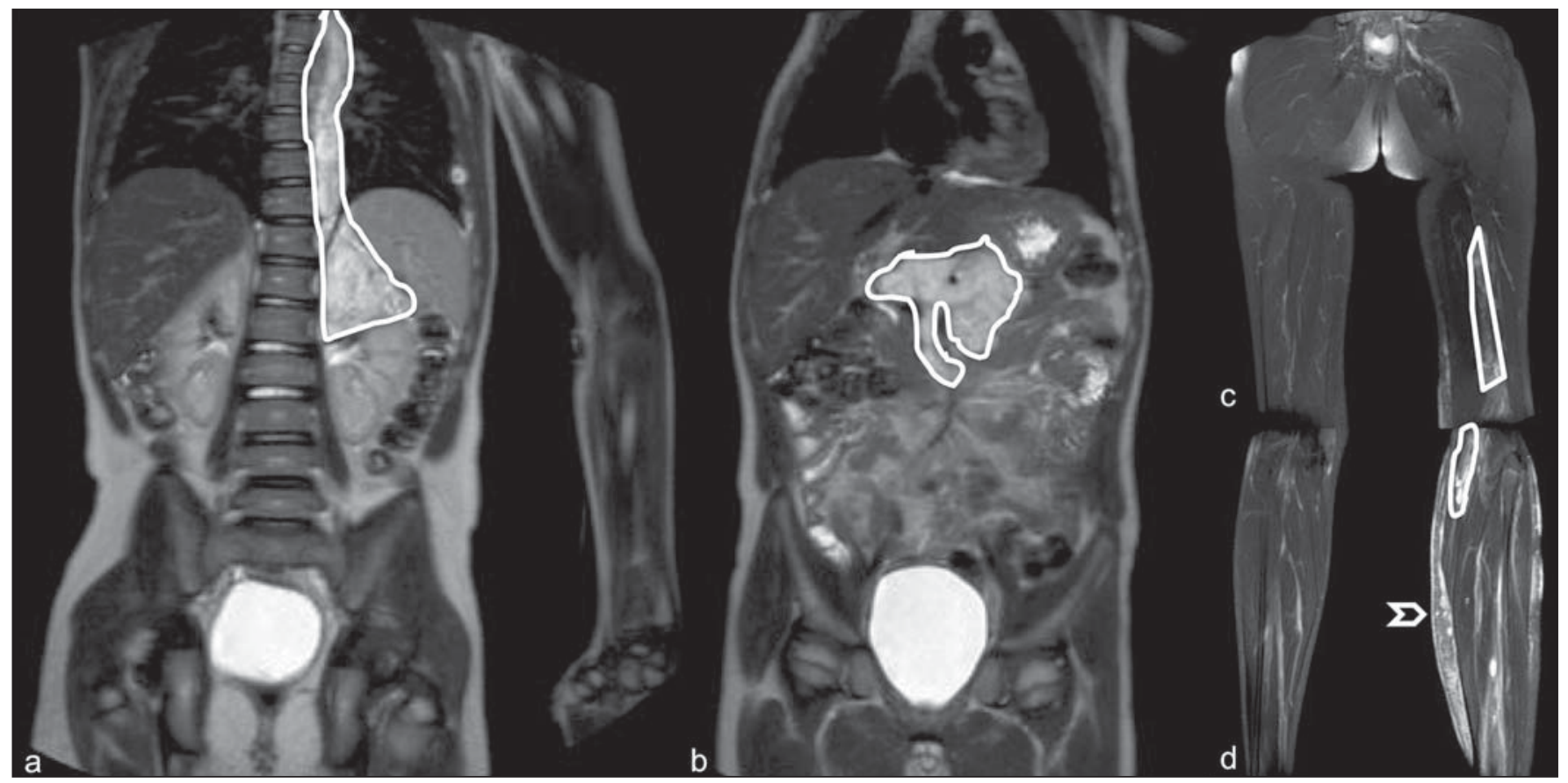

Figure 8. Evaluation of neurofibromas' burden in a patient with neurofibromatosis. Edema (arrowhead) is observed in left lower limb caused by vascular compression of neurofibromas. $\mathbf{a}$ and $\mathbf{b}$ : coronal T2-weighted TSE MR image of the trunk; $\mathbf{c}$ and $\mathbf{d}$ : coronal STIR MR image of the lower limbs.

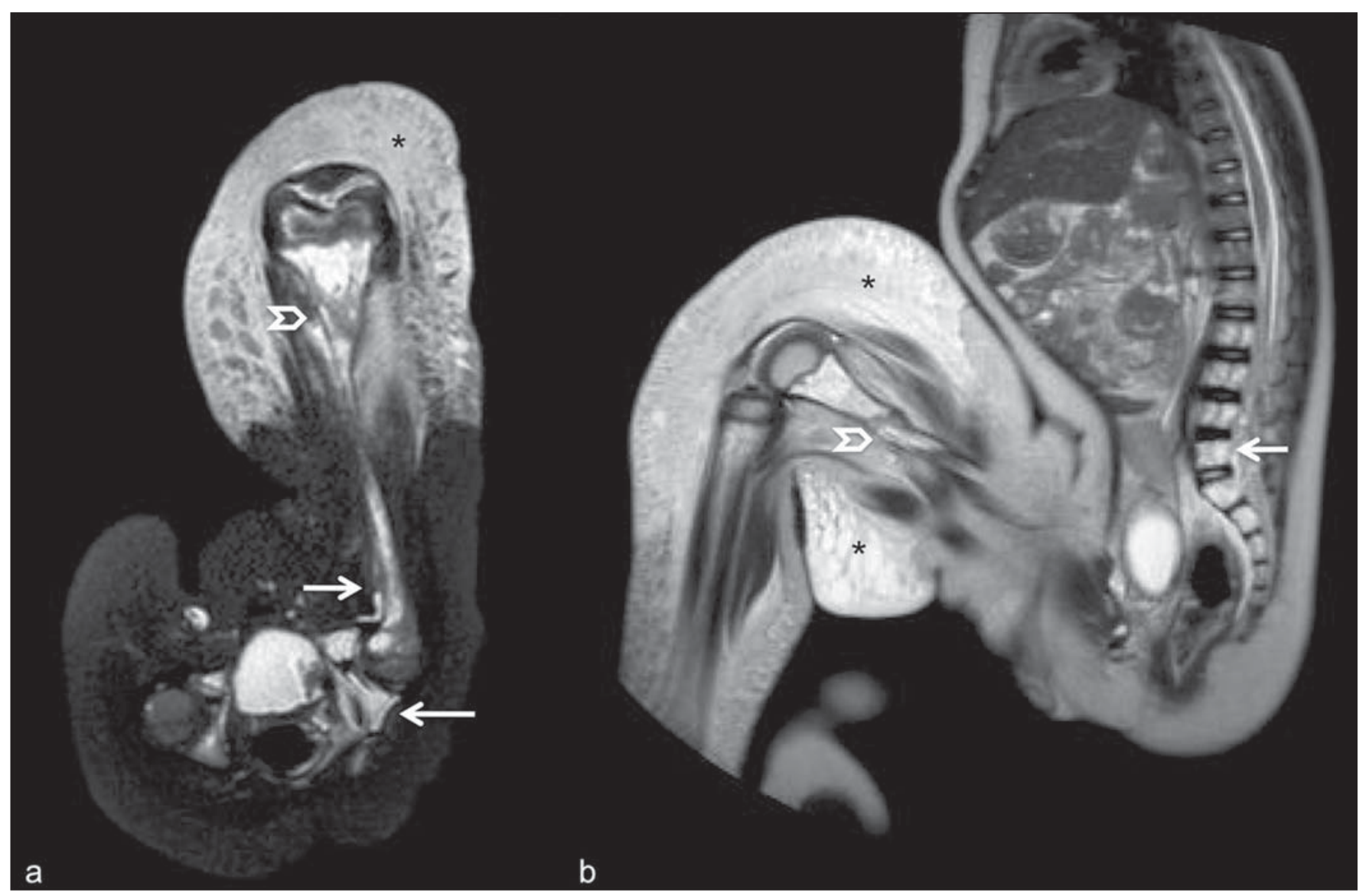

Figure 9. Evaluation of bone and visceral involvement in a 3-year-old boy with diffuse lymphangiomatosis (Gorham's disease). Sagittal plane was most appropriate due to deformities caused by disease. There is diffuse long bone, spine (arrows) and soft tissue (asterisks) lesions with hypersignal on T2-weighted and STIR images. A pathological fracture is noted in left femoral diaphysis (arrowhead). a: coronal STIR image of left lower limb; b: whole-body sagittal T2-weighted image. 


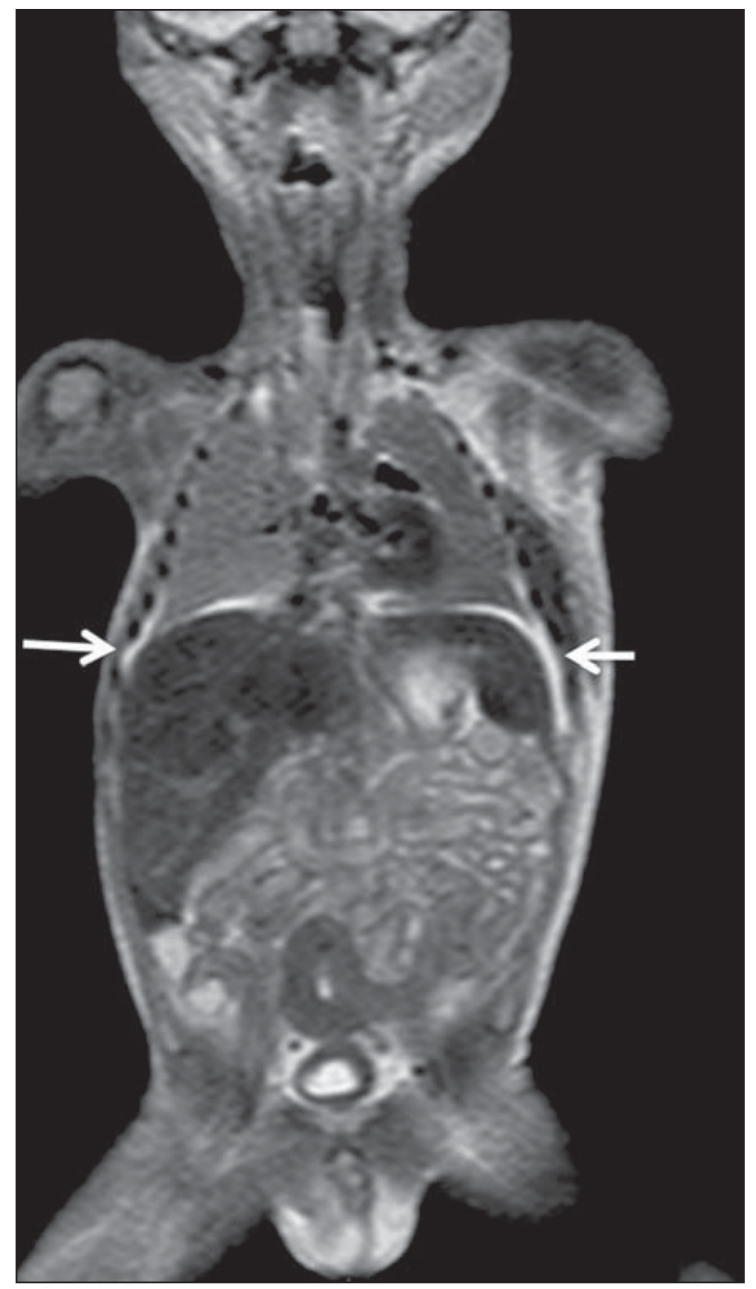

Figure 10. Virtual autopsy (coronal T2-weighted image) of a 26-week fetus with agenesis of the corpus callosum. Normal chest and abdomen. Presence of pleural effusion (arrows) is a normal post-mortem finding. (Image courtesy of Dr. Catherine Garel, Hôpital Armand-Trousseau, Paris, France).

tissue, muscles and deep tissues such as thoracic and abdominal organs and bone structures, WBMRI allows for identification of these lesions, their distribution and sites ${ }^{(11)}$. It is an excellent method for post-therapy evaluation and followup in these clinical scenarios ${ }^{(12)}$.

\section{Virtual autopsy}

In cases of fetal and neonatal death, autopsies are essential to predict future risks. WBMRI may be an alternative tool, allowing for less invasive and highly accurate wholebody evaluation ${ }^{(15,16)}$. However, despite its wide acceptance and relevance of the information provided by this method,

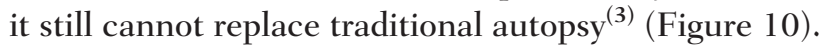

\section{WBMRI LIMITATIONS}

WBMRI has some limitations that may difficult its use in pediatric clinical practice. Long acquisition time required for scan, ranging from 20 to 60 minutes, makes sedation necessary for a large number of patients, particularly those at lower age ranges. Artifacts related to respiratory motion, heartbeats and peristaltic motion may degrade images ${ }^{(56)}$.
Utilization of rapid image acquisition techniques with multichannel systems, body coils and parallel imaging is recommended to minimize occurrence of $\operatorname{artifacts}^{(56)}$. WBMRI still presents low sensitivity to detect small lesions $<6 \mathrm{~mm}$ at images acquired in coronal plane - the primary imaging plane most frequently used in WBMRI -, especially pulmonary lesions and lymph nodes ${ }^{(43,57)}$. Therefore, additional sequences in axial plane or DWI may be necessary, which leads to increase of acquisition time. Caution is required in use of intravenous paramagnetic contrast agent, since, although small, risk for allergic reaction is present. Additionally, risk for nephrogenic systemic fibrosis in pediatric patients should not be ignored ${ }^{(3,22)}$.

Interpretation of WBMRI may be difficult and also represent a limiting factor in pediatrics. Physiological heterogeneity of bone marrow in children poses a problem for nonexperienced radiologists at morphological and functional sequences, in addition to aliasing, respiratory motion, heartbeats and peristaltic artifacts ${ }^{(55)}$.

\section{RECENT ADVANCES}

Developments in high-field 3T MRI and body surface coil have brought better spatial resolution and signal-to-noise ratio, providing better-quality images. Technical increment and popularization of the method should allow for a gradual replacement of other conventional methods with WBMRI, especially in the field of oncology ${ }^{(22)}$. However, in $3 \mathrm{~T}$ scanners, there is increased incidence of magnetic susceptibility artifacts, particularly at diffusion-weighted sequences. Also, increased specific absorption rate is a limiting factor for fat suppression sequences $^{(39)}$.

TRacking Only Navigator echo (TRON) is also a brand new technique developed to reduce motion artifacts with a slight increase in scan time, but it still requires further clinical studies to be definitely established in routine protocols ${ }^{(39)}$.

\section{CONCLUSION}

Despite the lack of standardization in evaluation of multifocal lesions in pediatrics, WBMRI is among imaging methods of choice for that purpose. It is a method free from risks of ionizing radiation exposure and it is highly accurate compared to traditional whole-body imaging methods. Ability to provide morphological and functional information in a single scan makes this method quite attractive and promising in management of pediatric patients. However, one must consider that it can not be used for detailed anatomical evaluation but rather as screening and follow-up modality in evaluation of multifocal lesions.

\section{Acknowledgements}

To Dr. Catherine Garel, who kindly provided image shown on Figure 10.

\section{REFERENCES}

1. Brenner DJ. Estimating cancer risks from pediatric CT: going from the qualitative to the quantitative. Pediatr Radiol. 2002;32:22831 ; discussion 242-4. 
2. Atri M. New technologies and directed agents for applications of cancer imaging. J Clin Oncol. 2006;24:3299-308.

3. Darge K, Jaramillo D, Siegel MJ. Whole-body MRI in children: current status and future applications. Eur J Radiol. 2008;68:289-98.

4. Kellenberger CJ, Miller SF, Khan M, et al. Initial experience with FSE STIR whole-body MR imaging for staging lymphoma in children. Eur Radiol. 2004;14:1829-41.

5. Fritz J, Tzaribatchev N, Claussen CD, et al. Chronic recurrent multifocal osteomyelitis: comparison of whole-body MR imaging with radiography and correlation with clinical and laboratory data. Radiology. 2009;252:842-51.

6. Goo HW, Yang DH, Ra YS, et al. Whole-body MRI of Langerhans cell histiocytosis: comparison with radiography and bone scintigraphy. Pediatr Radiol. 2006;36:1019-31.

7. Castro TC, Lederman H, Terreri MT, et al. The use of joint-specific and whole-body MRI in osteonecrosis: a study in patients with juvenile systemic lupus erythematosus. Br J Radiol. 201 1;84:62 1-8.

8. O'Connell MJ, Powell T, Brennan D, et al. Whole-body MR imaging in the diagnosis of polymyositis. AJR Am J Roentgenol. 2002; 179:967-71

9. Schmidt GP, Reiser MF, Baur-Melnyk A. Whole-body imaging of the musculoskeletal system: the value of MR imaging. Skeletal Radiol. 2007;36:1109-19.

10. Cai W, Kassarjian A, Bredella MA, et al. Tumor burden in patients with neurofibromatosis types 1 and 2 and schwannomatosis: determination on whole-body MR images. Radiology. 2009;250:66573.

11. Stein-Wexler R. MR imaging of soft tissue masses in children. Magn Reson Imaging Clin N Am. 2009;17:489-507, vi.

12. Sermon A, Gruwez JA, Lateur L, et al. The importance of magnetic resonance imaging in the diagnosis and treatment of diffuse lymphangioma. Acta Chir Belg. 1999;99:230-5.

13. Perez-Rossello JM, Connolly SA, Newton AW, et al. Whole-body MRI in suspected infant abuse. AJR Am J Roentgenol. 2010;195: 744-50.

14. Thomas EL, Saeed N, Hajnal JV, et al. Magnetic resonance imaging of total body fat. J Appl Physiol. 1998;85:1778-85.

15. Alderliesten ME, Peringa J, van der Hulst VP, et al. Perinatal mortality: clinical value of postmortem magnetic resonance imaging compared with autopsy in routine obstetric practice. BJOG. 2003; 110:378-82.

16. Thayyil S, Sebire NJ, Chitty LS, et al. Post-mortem MRI versus conventional autopsy in fetuses and children: a prospective validation study. Lancet. 2013;382:223-33.

17. Kavanagh E, Smith C, Eustace S. Whole-body turbo STIR MR imaging: controversies and avenues for development. Eur Radiol. 2003;13:2196-205.

18. Eiber M, Dütsch S, Gaa J, et al. Diffusion-weighted magnetic resonance imaging (DWI-MRI): a new method to differentiate between malignant and benign cervical lymph nodes. Laryngorhinootologie. 2008;87:850-5.

19. Koh DM, Padhani AR. Diffusion-weighted MRI: a new functional clinical technique for tumour imaging. Br J Radiol. 2006;79:6335.

20. Vilanova JC, Barcelo J. Diffusion-weighted whole-body MR screening. Eur J Radiol. 2008;67:440-7.

21. Schaefer JF, Kramer U. Whole-body MRI in children and juveniles. Rofo. 2011;183:24-36.

22. Goo HW. Regional and whole-body imaging in pediatric oncology. Pediatr Radiol. 2011;41 Suppl 1:S186-94.

23. Chavhan GB, Babyn PS. Whole-body MR imaging in children: principles, technique, current applications, and future directions. Radiographics. 2011;31:1757-72.

24. Takahara T, Kwee T, Kibune S, et al. Whole-body MRI using a sliding table and repositioning surface coil approach. Eur Radiol. 2010;20:1366-73.

25. Schaefer JF, Schlemmer HP. Total-body MR-imaging in oncology. Eur Radiol. 2006;16:2000-15.

26. Ley S, Ley-Zaporozhan J, Schenk JP. Whole-body MRI in the pediatric patient. Eur J Radiol. 2009;70:442-51.

27. Koh DM, Collins DJ. Diffusion-weighted MRI in the body: applications and challenges in oncology. AJR Am J Roentgenol. 2007; 188:1622-35.

28. Hirsch W, Krohmer S, Kluge R, et al. Preliminary results in wholebody MRI in children - a prospective study [abstr]. Pediatr Radiol. 2005;35(Suppl):S89.

29. Mazumdar A, Siegel MJ, Narra V, et al. Whole-body fast inversion recovery MR imaging of small cell neoplasms in pediatric patients: a pilot study. AJR Am J Roentgenol. 2002;179:1261-6.

30. Daldrup-Link HE, Franzius C, Link TM, et al. Whole-body MR imaging for detection of bone metastases in children and young adults: comparison with skeletal scintigraphy and FDG PET. AJR Am J Roentgenol. 2001;177:229-36.

31. Kellenberger CJ, Epelman M, Miller SF, et al. Fast STIR wholebody MR imaging in children. Radiographics. 2004;24:1317-30.

32. Siegel MJ, Luker GG. Bone marrow imaging in children. Magn Reson Imaging Clin N Am. 1996;4:771-96.

33. Meyer JS, Siegel MJ, Farooqui SO, et al. Which MRI sequence of the spine best reveals bone-marrow metastases of neuroblastoma? Pediatr Radiol. 2005;35:778-85.

34. Goo HW. Whole-body MRI of neuroblastoma. Eur J Radiol. 2010; 75:306-14

35. Hansen T, Wikström J, Eriksson MO, et al. Whole-body magnetic resonance angiography of patients using a standard clinical scanner. Eur Radiol. 2006;16:147-53.

36. Padhani AR, Liu G, Koh DM, et al. Diffusion-weighted magnetic resonance imaging as a cancer biomarker: consensus and recommendations. Neoplasia. 2009;11:102-25.

37. Takahara T, Imai Y, Yamashita T, et al. Diffusion weighted whole body imaging with background body signal suppression (DWIBS) technical improvement using free breathing, STIR and high resolution 3D display. Radiat Med. 2004;22:275-82.

38. Kwee TC, Takahara T, Ochiai R, et al. Whole-body diffusionweighted magnetic resonance imaging. Eur J Radiol. 2009;70:409_ 17.

39. Murtz P, Krautmacher C, Traber F, et al. Diffusion-weighted wholebody MR imaging with background body signal suppression: a feasibility study at 3.0 Tesla. Eur Radiol. 2007;17:3031-7.

40. Siegel MJ, Acharyya S, Hoffer FA, et al. Whole-body MR imaging for staging of malignant tumors in pediatric patients: results of the American College of Radiology Imaging Network 6660 Trial. Radiology. 2013;266:599-609.

41. Goo HW, Choi SH, Ghim T, et al. Whole-body MRI of paediatric malignant tumours: comparison with conventional oncological imaging methods. Pediatr Radiol. 2005;35:766-73.

42. Ballon D, Watts R, Dyke JP, et al. Imaging therapeutic response in human bone marrow using rapid whole-body MRI. Magn Reson Med. 2004;52:1234-8.

43. Punwani S, Taylor SA, Bainbridge A, et al. Pediatric and adolescent lymphoma: comparison of whole-body STIR half-Fourier RARE MR imaging with an enhanced PET/CT reference for initial staging. Radiology. 2010;255:182-90.

44. Kumar J, Seith A, Kumar A, et al. Whole-body MR imaging with the use of parallel imaging for detection of skeletal metastases in pediatric patients with small-cell neoplasms: comparison with skeletal scintigraphy and FDG PET/CT. Pediatr Radiol. 2008;38:95362.

45. Daldrup-Link HE, Franzius C, Link TM, et al. Whole-body MR 
imaging for detection of bone metastases in children and young adults: comparison with skeletal scintigraphy and FDG PET. AJR Am J Roentgenol. 2001;177:229-36.

46. Karmazyn B, Cohen MD, Jennings SG, et al. Marrow signal changes observed in follow-up whole-body MRI studies in children and young adults with neurofibromatosis type 1 treated with imatinib mesylate (Gleevec) for plexiform neurofibromas. Pediatr Radiol. 2012;42: 1218-22.

47. Li SP, Padhani AR. Tumor response assessments with diffusion and perfusion MRI. J Magn Reson Imaging. 2012;35:745-63.

48. Padhani AR, Khan AA. Diffusion-weighted (DW) and dynamic contrast-enhanced (DCE) magnetic resonance imaging (MRI) for monitoring anticancer therapy. Target Oncol. 2010;5:39-52.

49. Herman M, Paucek B, Raida L, et al. Comparison of magnetic resonance imaging and (67)gallium scintigraphy in the evaluation of posttherapeutic residual mediastinal mass in the patients with Hodgkin's lymphoma. Eur J Radiol. 2007;64:432-8.

50. Ducreux M, Mateus C, Planchard D, et al. Screening and early diagnosis of other cancers (non-small cell lung carcinoma, urologic cancers, liver cancer and melanoma). Rev Prat. 2010;60:219-23.

51. Testa JR, Malkin D, Schiffman JD. Connecting molecular pathways to hereditary cancer risk syndromes. Am Soc Clin Oncol Educ Book. 2013:81-90.
52. Villani A, Tabori U, Schiffman J, et al. Biochemical and imaging surveillance in germline TP53 mutation carriers with Li-Fraumeni syndrome: a prospective observational study. Lancet Oncol. 2011; 12:559-67.

53. Krohmer S, Sorge I, Krausse A, et al. Whole-body MRI for primary evaluation of malignant disease in children. Eur J Radiol. 2010;74: 256-61.

54. Butter F, Pohle C, Girschick H, et al. Chronic non-bacterial osteomyelitis $(\mathrm{CNO})$ : findings in the initial diagnostic imaging [conference paper]. Eur Radiol. 2004;B775(14S).

55. Alison M, Tilea B, Azoulay R, et al. IRM corps entier en pédiatrie: quand, comment, pourquoi? XXXIIIèmes Journées de Trousseau 2011. [acessado em 2 de setembro de 2013. Disponível em: www. sfip-radiopediatrie.org/images/stories/Textes_reference/ ref_locomoteur/alison_trousseau_2011.pdf.

56. Koh DM, Blackledge M, Padhani AR, et al. Whole-body diffusionweighted MRI: tips, tricks, and pitfalls. AJR Am J Roentgenol. 2012; 199:252-62.

57. Frericks BB, Meyer BC, Martus P, et al. MRI of the thorax during whole-body MRI: evaluation of different MR sequences and comparison to thoracic multidetector computed tomography (MDCT). J Magn Reson Imaging. 2008;27:538-45. 